\title{
Modifications to a Freshman Engineering Course Based on Student Feedback
}

\author{
Leo H. McWilliams, Stephen E. Silliman, Catherine Pieronek \\ University of Notre Dame
}

\begin{abstract}
The University of Notre Dame's freshman engineering course is designed both to provide students with foundational skills in engineering and to provide information necessary for the students to make informed decisions when selecting a major. It was noted during the prior two academic years that a significant number of students $(\sim 10-15 \%)$ withdrew from the course (and, therefore, from engineering) prior to the midterm exam in the first semester. Two primary factors were reported for withdrawals within the first seven weeks of the course. First, students indicated significant apprehension regarding the level of programming required (programming had been added to the first project in 2001). Second, a number of the students who withdrew were convinced (without firm evidence) that the majority of other students in the course were more proficient at programming.
\end{abstract}

These observations led to modifications to the first project with the dual goals of improving the educational experience for the students and retaining a greater percentage of students through the first semester. First, the emphasis was changed from programming and physics to engineering as an application of math, science and computing. The students now utilize existing computer packages, rather than developing their own programs, to assist in the development of an engineering solution. This allows students to focus on design rather than on the details of programming. Second, an Audience Response System (ARS) now provides immediate student feedback during lectures. The ARS is used to query students regarding the pace of the course and their comprehension of the material. The responses have demonstrated to both the faculty and the students that there is tremendous diversity among the students in terms of skills and understanding. Third, the opening lecture and select applications have been geared towards altruistic reasons for remaining in engineering. Fourth, evening "help" sessions are offered on a regular basis to provide struggling students with access to regularly scheduled review and assistance.

As a result of these changes, approximately $99 \%$ of the students that were enrolled on the last formal day to add courses (considered the day on which students have committed to taking the course) completed the first semester course. Nearly $77 \%$ of these students were also enrolled in the second semester course. Student feedback indicates that, while some intimidation remains regarding the use of computers, the delay in the introduction of programming and the knowledge that other students are "in the same boat" is a major factor in providing students with the confidence to complete the course. 


\section{Introduction}

The end of the Spring 2003 semester marked the completion of the third year of the Introduction to Engineering Systems course sequence in the College of Engineering at the University of Notre Dame (the sequence is designated EG 111/112). Introduction to Engineering Systems is a twosemester, six credit hour course sequence for first-year students intending to major in engineering. Development and implementation of this course sequence arose based on efforts to improve the quality of the first-year experience within the engineering curriculum (e.g., Brockman et al. ${ }^{1}$ ). Retention was not considered to be a defining concern in the original design of the course sequence. During the past three years, the course sequence has been modified in both format and content with the primary motivation to improve the learning experience.

Monitoring of retention statistics, student surveys and exit interviews has provided valuable insight into the effectiveness of the course. Generally, these sources of data have shown the course to be a success in terms of the primary learning objectives. Among the challenges identified based on data for the past two academic years, however, was the relatively high withdrawal rate of students (above 10\% - see Table 1) from the first semester course. This is viewed as being problematic as these students have therefore not had the opportunity to be exposed to a balanced presentation of the engineering profession. Further, due to the timing of the last permissible date to withdraw from a course, the vast majority of the students withdrawing from the course do so prior to completing the first project or taking the first exam. Hence, these students withdraw prior to receiving formal evaluation of the quality of their work.

\begin{tabular}{|c|c|c|c|}
\hline & Fall 2000 & Fall 2001 & Fall 2002 \\
\hline First Year Students Starting EG 111 & 369 & 359 & 354 \\
\hline First Year Students Completing EG 111 & 355 & 314 & 315 \\
\hline \% Retained & $96.2 \%$ & $87.2 \%$ & $88.9 \%$ \\
\hline
\end{tabular}

Table 1 Three-Year Enrollment and Retention Data

Assessment of the reasons for the high withdrawal rate during the past two academic years allowed identification of the following three issues:

- $\quad$ The perception among a number of students (including both those who withdrew and students who remained in the course) that their skills in computer programming were considerably weaker than the skills of their fellow students.

- $\quad$ The perception that the level of computer programming required in the first project was overwhelming for a significant number of students.

- $\quad$ The perception that the lectures were of limited value with respect to the final grade received by the student.

The College responded to this assessment by formulating a set of modifications to the first

Proceedings of the 2004 American Society for Engineering Education Annual Conference \& Exposition Copyright $\mathbb{C}$ 2004, American Society for Engineering Education 
semester course. In considering modifications to the course, the primary goal remained to improve the quality of the learning experience. However, student retention and student satisfaction with the learning experience were significant secondary considerations. These modifications were implemented in the Fall 2003 version of the course. This paper details the modifications to the first semester course as well as the results of these modifications through the completion of the first semester.

\section{Description of EG 111/112}

The details of the motivation and development of EG 111/112 have been discussed by Brockman et al. ${ }^{1}$ in a previous ASEE publication. The course web site provides additional information on the basic structure and content of the course (www.nd.edu/ engintro).

EG 111/112 is organized into 11-14 sections each with no more than 30 students per section. Each section is led by a faculty member and supported by a student peer mentor. Typically, six to eight faculty members are assigned to teach the course during a semester. Notre Dame requires all engineering intents to take the EG 111/112 course sequence.

Although the format was revised for Spring 2004, the format of the course from conception through Fall 2003 involved large lectures, individual learning sections, and recitations. Lectures were given in a large lecture hall with 3 lectures given to the group in every two-week period of the semester. Individual sections met in the Engineering Learning Center (www.nd.edu/ englearn) each week for a series of individual or small group activities that enhanced or supplemented the large lectures. Every other week, each section also met in a classroom setting for a recitation where the students could ask questions, review homework problems, work on the projects or receive additional supplemental material from the faculty members teaching the course. (Details of modifications made in Spring 2004 are beyond the scope of this manuscript.)

EG 111/112 is based on four multidisciplinary projects, or modules, each requiring a halfsemester to complete. Each project is based on a series of learning objectives. Students work in groups of no more than five to design, implement, test and demonstrate a system or process that meets a set of requirements listed in a project specific Technical Specification. The deliverables for the project, key milestones and other process related project information are listed in a project specific Statement of Work (SOW).

The content of the four modules and format of the course have remained approximately the same over the past three academic years. However, two significant changes did occur between the first and second administration of the course. The first involved altering the course to include more technical content and less content on topics such as the nature and history of engineering and the role of the engineer in society. The other involved introducing programming earlier in the academic year (moved from the spring semester forward to the first project in the fall semester). 


\section{Retention in Prior Semesters and Analysis of Motivation for Withdrawing from EG 111}

Each year, the course seeks feedback from various sources. Students are requested to complete surveys during the first two weeks of the first semester and during the final weeks of the second semester. Additional feedback is sought from students during each semester, particularly if a student elects to withdraw from the course. Feedback is also sought from the freshman year advising team and from college faculty regarding student reaction to the course and student learning occurring in the course as reflected both in student projects and in student performance after the freshman year.

In a recent paper, Pieronek et al. ${ }^{2}$ presented initial results relative to retention statistics, and student surveys. Retention over the first three offerings of EG 111/112 was calculated and trends were determined. It was observed that changes in the first semester course appeared to influence the rate of withdrawal of students prior to completion of the first semester, especially for women. Women were also retained at a significantly lower rate than men. These results encouraged the College to consider modifications to the first semester course. The study of the retention and gender issue continues; Pieronek et al. ${ }^{3}$ provide a more in depth examination of the retention rates, with particular emphasis on gender differentials.

A summary of the retention rates for the first semester course is presented in Table 1 above. The rates reported in this paper as well as in Pieronek et al. ${ }^{3}$ represent a revision to those presented in Pieronek et al. ${ }^{2}$ Specifically, efforts have now been undertaken to identify only the first year students in the class (some sophomore students also enroll). It is noted parenthetically that the revised data continue to support the conclusions reported in the earlier paper.

A significant drop in retention through the first semester course was observed in the Fall 2001 and Fall 2002 offerings as compared to the Fall 2000 offering. Feedback from various sources, including interviews of students who discontinued the course, indicated a significant level of student intimidation by, and frustration with, the programming component in the first module. Recall that a major change implemented between the 2000/1 and 2001/2 academic years was the introduction of programming in the first module of the first semester.

In addition to simple retention, interest was expressed in the timing of student withdrawals from the first semester course. A student who elects to discontinue the course prior to the end of the semester, must submit an administrative course discontinuance form. While this submission does not capture the exact point at which this student begins to reconsider the choice of major; it does capture the point at which this student elects to act on this decision. This submission makes it possible to assess and compare the timing of student withdrawals from the course relative to significant milestones in the course.

One significant milestone in the first semester course is the first examination typically scheduled during the week prior to mid-semester break. This exam provides the first class-wide assessment of student performance in the class and commonly coincides with the submission of the project report for the first module. Completing the first examination is a direct indication that the 
student has completed at least one full engineering project and has received formal feedback relative to their performance in the course. Thus, students withdrawing from the course prior to this exam both fail to complete the first project with their project team and are making their decision to drop without formal measures of their performance.

Table 2 provides a summary of withdrawals prior to and after the first exam for the first three offerings of the course. In the Fall 2000 offering, half of the withdrawals were prior to the first exam. The following two years, this increased to approximately $75 \%$ and $79 \%$, respectively. This increased percentage of withdrawals prior to the exam is interpreted as an indication that the students were dissatisfied with the presentation of the first module in 2001 and 2002.

\begin{tabular}{|c|c|c|c|}
\hline & Fall 2000 & Fall 2001 & Fall 2002 \\
\hline Drops Prior to first examination & 7 & 34 & 31 \\
\hline Drops after the first examination & 7 & 11 & 8 \\
\hline Total through EG 111 & 14 & 45 & 39 \\
\hline
\end{tabular}

Table 2 Timing of Student Withdrawal from EG 111

Due to the observed drop in retention following the introduction of programming, the entrance survey was modified in Fall 2002 to ask the students to rate themselves with respect to: (i) their ability to program a computer, and (ii) their ability to run applications on a computer. Table 3 summarizes the Fall 2002 survey results. A significant difference in the student's self assessment of these two skills is observed. While many of the students felt comfortable using existing programs on a computer, a significant percentage of the students felt uncomfortable with their personal skill in programming.

\begin{tabular}{|c|c|c|}
\hline & $\begin{array}{c}\text { Program a computer } \\
(\mathbf{\%})\end{array}$ & $\begin{array}{c}\text { Run an application on a } \\
\text { computer (\%) }\end{array}$ \\
\hline Very Poor & 10.3 & 0.6 \\
\hline Poor & 31.9 & 6.2 \\
\hline Fair & 31.9 & 25.2 \\
\hline Good & 17.5 & 36 \\
\hline Very Good & 8.4 & 32 \\
\hline
\end{tabular}

Table 3 Self assessment of computer skills

\section{Modifications to the First Semester Course}

Based on the assessment of student retention and student satisfaction with the fall semester course (EG 111), the College of Engineering examined a number of possible modifications to the 
course that would both improve student satisfaction with the course and encourage more students to complete the first semester prior to making a decision to leave the engineering curriculum. Modifications that were selected for implementation in the fall of 2003 included:

1. Modify the motivation and student activities within the first module.

2. Utilize technology to provide the students more active mechanisms for providing feedback to the faculty and their fellow students

3. Modify the content of the lectures and the format for presenting the lectures.

4. Provide "help" sessions in the evenings to assist students who were struggling with course material.

\section{Modifications to the Motivation and Student Activities in the First Module}

Modifications of the portion of the course occurring prior to the first examination involve modifications of the first course module, herein referred to as the "Launch Project". The educational objectives of this project are to

- Demonstrate problem decomposition in order to aid in engineering design.

- Understand the interplay of applied science, math, and the use of computers in engineering design.

These objectives are met by requiring student teams to launch a softball at a specified target so as to achieve an error in the launch distance of less than 5\%. In the project, the students are organized into teams, are provided with a launcher and a softball. The teams are expected to use a series of computer programs that simulate certain parts of the launch/flight process in order to develop a logical process to use on launch day to deliver the softball to the target.

The students are shown that the launch process can be decomposed into a propulsion process, a launch process and a ground control process. They are presented with the relevant principles, laws and concepts from mathematics and science for understanding of the process and development of the models. They are required to develop the launch procedure through consideration of the decomposition of a complex problem into a series of manageable tasks.

A number of modifications were made to this project in the most recent offering (Fall 2003):

- the emphasis of the first project was changed from programming and physics to an application of math, science and engineering

- the programming requirement was replaced with a series of exercises focused on the use of the computer as a tool in developing an engineering solution

- the procedure was stressed more heavily than was success in "hitting the target"

- $\quad$ teams and faculty were allowed an opportunity to evaluate student designs prior to the formal demonstration

- the evaluation criteria for the formal demonstration was modified to reflect the changes above

Proceedings of the 2004 American Society for Engineering Education Annual Conference \& Exposition Copyright $(\mathrm{C} 2004$, American Society for Engineering Education 
Prior to the 2003/2004 offering of EG 111, the teams were required to develop a numerical simulation of the propulsion and flight dynamics of the softball. This simulation was then used as a basis for development of the launch procedure. In the initial offering of EG 111 (Fall 2000), Microsoft Excel spreadsheets were developed as the simulator. Due to general student dissatisfaction with the use of Excel, the second and third offerings of the course were based on the students developing MATLAB programs. Thus, in addition to understanding and applying Newton's Laws, Conservation of Energy, drag, work vs. energy, vectors and numerical integration algorithms (Euler and trapezoidal), programming skills and concepts such as loops, conditionals, arrays and plot commands were required.

In the Fall 2003 offering of EG 111, the requirement for the students to develop MATLAB programs was removed. The students were provided existing MATLAB programs as a basis for simulating their launch process. The time previously spent on programming was applied to discussion of problem decomposition and the application of math, science, and the computer in engineering. This allowed the students to focus on the science, mathematics and engineering decision making process. The only programming required of the students was that necessary to interface (input/output commands) with the programs provided. Within this new pedagogy, the students remain responsible for the application of the math and science concepts upon which the simulations are based. Further, the MATLAB script files were provided to allow inquisitive students the ability to "look under the hood" at the construction of the program.

Prior to the 2003/2004 offering of EG 111, the project teams were allotted 15 minutes to launch the softball to three target distances provided by the faculty or peer mentor on the day of demonstration. Each team had the opportunity to perform one "calibration" launch to establish launcher characteristics. After this calibration launch, the team was given one opportunity to hit each target with grades based on the magnitude of the error in the observed launch distance. This activity was typically one-third of the team's final project grade with no direct points awarded for execution of the procedure, only the ability to "hit" the target. As such, a team could potentially receive full credit for hitting all targets while not following the procedure that they developed.

This previous fall, the focus was changed to a demonstration of the launch procedure. Each project team provided a copy of their procedure to the faculty member or student grader to follow for review and evaluation. Multiple launches were allowed at a single target. The target was assumed to be hit if the magnitude of the error was $\leq 5 \%$. The students were evaluated on factors such as ability to follow the procedure and their analysis of previous launch results to determine new launcher settings.

One final change to the project was to allow each project team an opportunity to test its procedure in the week prior to the formal demonstration. This modification was adopted based on feedback from students previously in the class and to follow an engineering process that allows testing prior to final shipment of a product. 


\section{Use of Technology to Improve Student Feedback}

The University of Notre Dame has recently acquired an Audience Response System (ARS) for course use. In a companion paper, Silliman and McWilliams ${ }^{4}$ describe the ARS technology in use at Notre Dame and present their observations on benefits and limitations of such a technology in various educational settings.

The use of an ARS was an integral component of the College's response to the issues identified in the assessment of EG 111/112. The ARS establishes a means of providing real-time, two-way communication between the student and the faculty during lectures. The faculty has a means to engage the student during the large lectures, identify topics that may need to be revisited and gather additional relevant information. Through display of the results to the class, the students are able to compare themselves to other classmates, answer questions in a non-intimidating environment and remain engaged with the lecturer.

The ARS used in EG 111 allows the students to respond to multiple choice questions posed during lecture. Students are provided with hand-held response units for keying in their responses. These units transmit responses to a receiver that interfaces with a computer. The associated software package allows collection and processing of the responses from the units and real-time display of the results in the format selected by the faculty member. The system has the capability to collect responses anonymously or track individual students at the faculty member's option. Further, the system allows both questions and demographics to be collected.

The ARS was used in a variety of fashions during the lectures. Among the most powerful, and a means of directly addressing the student perception that others in the class had better programming skills, was to use the ARS to provide the students with class-wide assessments in real-time. The overall approach was to use the ARS to survey the students at different times throughout the semester on their comfort with the objectives of the project and the level of computer work. As an example of the type of response received, Table 4 summarizes student responses at two different periods during the project.

\begin{tabular}{|c|c|c|}
\hline What is your comfort level with the computer work so far? & Sept. 15 & Oct. 10 \\
\hline Want to start programming & $24 \%$ & $35.8 \%$ \\
\hline Want to use them more but not program yet & $40 \%$ & $26.2 \%$ \\
\hline Good as it is & $20 \%$ & $16.1 \%$ \\
\hline Doing too much & $14 \%$ & $8 \%$ \\
\hline
\end{tabular}

Table 4 Response to the question "What is your comfort level with the computer work so far?" 
The results in Table 4, shown in real-time to the students during the lecture, had at least three impacts on the course and student satisfaction with the course. First, the students who were present in lecture on September 15 were able to observe that there is a tremendous variation in comfort level with respect to computing. This had the effect of providing the more advanced students with some understanding as to why the course was not introducing computing more quickly and providing the weaker students with the reassurance that they were "not alone" in their concerns over the computing required in the course. Second, these data provided direct evidence to the faculty involved in the design and administration of this course of the wide range of student comfort with the material being presented. Third, comparison of the responses on the two dates provides evidence of the impact of the course on student evaluation of their computing abilities. As an aside, it is believed that the large response to "doing too much" on October 10 may be the result of a group of students attempting to skew the results by repeatedly entering this response during the response period.\}

Beyond this ability to survey student opinion, the ARS provided the students with a means of reflecting and responding to lecture material. Towards this end, the lecturer placed multiple choice question slides at strategic points within lectures so as to challenge the students to remain attentive to the lectures. Student feedback regarding use of the ARS in this fashion was quite positive.

\section{Improving the Lectures}

In evaluations from the 2000/1, 2001/2, and 2002/3 academic years, students repeatedly indicated that the lectures were considered to be of limited value. Among the issues brought forth were a perceived disconnection between the lectures and the projects, the difficulty in determining important aspects of the lecture material, and dissatisfaction with the quality of some of the lectures.

It was hypothesized that the students had this reaction to the lectures for a number of reasons. These included: (i) the model being used to present lectures in which the faculty member giving the lecture was rotated on an essentially lecture-by-lecture basis, (ii) the range of talent among the faculty for presenting a lecture to a large audience, and (iii) the inability, without technology, for the students to feel connected to the lecturer, particularly during derivations. In response, the following modifications were performed:

- $\quad$ The first lecture focused strictly on the contributions of engineering to society

- $\quad$ At most, two lecturers/project were used to deliver the large lectures

- $\quad$ The ARS was used at selected times in the semester to increase student engagement

The modification to the first lecture was a direct result of our observation that women are retained in this course at a substantially lower rate than men [3]. A concern had been raised in prior offerings of the course that focusing too rapidly on the technical aspects of engineering 
without addressing the impact of engineering on society may result in women becoming disinterested at a rate disproportionately high as compared to the men. As a result, the focus of the first lecture in the course was changed to emphasize the previous contributions of engineers to society and to expose the students to the potential future contributions. This lecture brings into focus "life as an engineer after graduation" as opposed to "life in EG 111/112". By receiving this exposure early in this first course, the students were provided with an opportunity to develop ownership of their major and a mindset that will enable them to withstand the challenges of an engineering curriculum.

With respect to the number of lecturers giving the lectures in the first module, it was noted that in Fall 2002, the eight lectures corresponding to the first module were delivered by six of the seven faculty members in the course. Hence, for the most part, each lecture was delivered by a different lecturer. While the previous format exposes the students to the various lecturers and lecture styles of the faculty in the course, students can take advantage of this multi-lecturer environment only if they have the skills to recognize and adapt to the different lecture styles. This format also restricts the flexibility of the faculty lecturers as issues arising during one lecture are not as naturally addressed in the following lecture. Hence, during Fall 2003, the first module was presented by only two lecturers (and the second module was presented in its entirety by one lecturer). It was observed that using the reduced number of lecturers provided for more continuity among lectures and greater connection between the lectures and the other course activities.

Finally, as noted above, the ARS was utilized at various times throughout the semester to provide additional student engagement. While the use of the ARS sometimes led to periods of increased noise and activity among the student audience (such that the lecture could not continue without a request for quiet), the ARS seemed to have an immediate effect of engaging the students in the lecture material.

\section{Increasing the Number of Help Sessions}

The original design of the course sequence included a number of avenues whereby the students could seek assistance with course material. Students seeking immediate assistance can seek out student assistants (termed "Peer Mentors") in the Learning Center which is open until midnight most nights of the week. Peer mentors regularly staff the Learning Center when it is open. Students are also encouraged to either make an appointment or utilize the office hours of the faculty members involved in the course. The bi-weekly recitations also provide an opportunity for students to have their questions addressed. Finally, the Freshman Year program at Notre Dame offers tutoring and help for all freshman students.

For the Fall 2003 offering, it was decided that additional help sessions with Peer Mentors or the course manager would be instituted in the evenings. These sessions specifically targeted students having difficulty with the course content and were held in classrooms reserved for this activity. All of the students in the course were notified of the availability of these help sessions 
and were encouraged to attend. Typically, the help sessions took the form of student-led question and answer sessions. This encourages the students to review course material prior to attending the help sessions.

\section{Downstream effects}

It is noted that the changes made to the first module directly impacted the design of the remaining three modules. The most dramatic impact involved the loss of computer programming in the first module and its impact on the second module. The second module requires the students to develop an autonomously controlled robot to perform a series of tasks. Students must develop the control software for their robot design using the NQC language. In the previous two years, this project was not started until after mid-semester break. This was done to allow the students to continue to develop their proficiency in MATLAB programming prior to the introduction of NQC. Hence, NQC was effectively a second language for the students at the beginning of the second module.

As a result of the modifications to the first module, NQC has become the first exposure to programming for many of the students. To accommodate the extra material that was needed to introduce the basics of programming, the duration of module 2 was extended. Specifically, the initial lectures for the second module occurred prior to completion of the student projects for the first module. The delivery and workload of module 2 was managed to provide first exposure prior to mid-semester break and to ramp up module 2 once the first project was completed.

MATLAB is now introduced in the third module of the course. As would be expected, this has led to a substantial revision of this module from a project focused on design (and construction of a static structure) to problem decomposition for the purpose of programming.

\section{Results and Observations}

Table 5 summarizes the retention results for Fall 2003. It is apparent from these data that the retention was higher in this past semester than in any of the previous offerings of EG 111. A total of five students dropped the course. Of the students electing to drop the course, three dropped prior to the first examination while two dropped after the exam.

\begin{tabular}{|c|c|}
\hline & Fall 2003 \\
\hline First Year Students Starting EG 111 & 366 \\
\hline First Year Students Completing EG 111 & 361 \\
\hline \% Retained & $98.6 \%$ \\
\hline
\end{tabular}

Table 5 Retention Summary for Fall 2003 Offering

As important as the retention of students through the first course is retention of students into the second course (and, eventually, students to graduation). Table 6 provides a summary of the 
retention of the course sequence through the start of EG 112 for the past four freshman classes. As with the results presented in Table 5 for retention through the first semester, these data show that a higher percentage of students are retained into the second semester of the freshman year. These same students will be monitored throughout the remainder of their college careers to determine overall retention through graduation.

\begin{tabular}{|c|c|c|c|c|}
\hline & Fall 2000 & Fall 2001 & Fall 2002 & Fall 2003 \\
\hline First Year Students Starting EG 111 & 369 & 359 & 354 & 366 \\
\hline First Year Students Starting EG 112 & 271 & 262 & 259 & 280 \\
\hline \% Retained & $73.4 \%$ & $73.1 \%$ & $73.16 \%$ & $76.05 \%$ \\
\hline
\end{tabular}

Table 6 A summary of student retention through the start of EG 112

Assessment of these retention numbers indicates that the changes made in the first semester have had positive impact on retention.

It must be cautioned, however, that additional study and modification of this course will be necessary. Among the issues that remain for further study are:

1. Gender Bias in the retention rates: Pieronek et al. ${ }^{3}$ discuss some of the issues that are being studied in terms of differential retention of students by demographic group. Demographics that appear to be of primary importance are gender and initial declaration of proposed major on the application for admission to Notre Dame.

2. Student evaluations completed at the end of the semester indicate that further improvement could be realized in the lectures. Specifically, the students were asked how the course could be improved (a question not necessarily directed at lectures). While many students indicated that no improvements in the course were needed, some comments towards the lectures were received.

3. The student population in the course remains diverse. This is reflected, for example, in student surveys that show that approximately equal numbers of students consider the pace of the course to be too slow versus too fast. Hence, an issue remains as to how best to present a single freshman course to such a diverse audience without intimidating students with weaker backgrounds or boring students with superior backgrounds. 
References

1. Brockman, J.B., Fuja, T.E, Batill, S.M., "A Multidisciplinary Course Sequence for First-Year Engineering Students,” 2002 ASEE Annual Conference and Exposition, Montreal, Quebec, Canada, June 2002.

2. Pieronek, C. , McWilliams, L. H., Silliman, S. E., "Initial Observations on Student Retention and Course Satisfaction Based on First-Year Engineering Student Survey and Interviews," 2003 ASEE Annual Conference and Exposition, Nashville, Tennessee, June 2003.

3. Pieronek, C. , McWilliams, L. H., Silliman, S. E., "A Demographic Characterization of First-Year Engineering Students," 2004 ASEE Annual Conference and Exposition, Salt Lake City, Utah, June 2004.

4. Silliman, S. E., McWilliams, L. H., "Observations on Benefits/Limitations of an Audience Response System," 2004 ASEE Annual Conference and Exposition, Salt Lake City, Utah, June 2004.

\section{LEO H. McWILLIAMS}

Dr. Leo H. McWilliams has served as course coordinator for the First-Year Engineering Program at the University of Notre Dame since 2001. Prior to joining Notre Dame in this capacity, he worked as a principal engineer at Honeywell International. Dr. McWilliams received his B.A. in economics, B.S.E.E., M.S.E.E. and Ph.D. from the University of Notre Dame.

\section{STEPHEN E. SILLIMAN}

Dr. Stephen E. Silliman is a professor of civil engineering and geological sciences and an associate dean for undergraduate programs in the College of Engineering at the University of Notre Dame. He joined the faculty in 1986, and his primary area of research is in groundwater hydrology with recent focus on water resources in developing countries.

\section{CATHERINE PIERONEK}

Catherine Pieronek, J.D., has directed the Women's Engineering Program at the University of Notre Dame since 2002. She has worked as a senior systems engineer on NASA spacecraft projects at TRW Space \& Defense Sector, and as director of external relations for the Notre Dame Law School. She earned her B.S.A.E. from the University of Notre Dame, her M.S.A.E. from UCLA, and her J.D. from the Notre Dame Law School. 